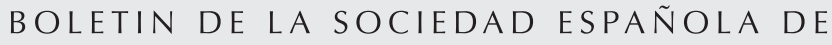

\section{Opacificación de vidrio sonoro superior}

\author{
Cristina Gil ${ }^{a, *}$, Fernando Agua ${ }^{b}$ y María-Ángeles Villegas ${ }^{b}$ \\ a Facultad de Educación, Campus María Zambrano, Universidad de Valladolid, Segovia, España \\ ${ }^{\mathrm{b}}$ Instituto de Historia, Consejo Superior de Investigaciones Científicas, Madrid, España
}

\section{INFORMACIÓN DEL ARTÍCULO}

Historia del artículo:

Recibido el 4 de junio de 2019

Aceptado el 11 de septiembre de

2019

On-line el 6 de noviembre de 2019

\section{Palabras clave:}

Vidrio sonoro

Opacificante

Opalina

Fluorita

\section{R E S U M E N}

Dado el interés histórico, artístico y tecnológico de las opalinas de la Real Fábrica de Cristales, se han formulado vidrios opales utilizando como opacificantes $\mathrm{CaF}_{2}$ y $\mathrm{P}_{2} \mathrm{O}_{5}$. El objetivo es obtener una composición compatible con el proceso de fabricación de la Fundación Centro Nacional del Vidrio usando el vidrio sonoro regularmente utilizado para la reproducción de piezas históricas. Los vidrios opales obtenidos se han caracterizado por espectrofotometría visible, difracción de rayos $\mathrm{X}$, microscopia electrónica de barrido de emisión de campo y microanálisis de dispersión de energías de rayos X. Además, en los vidrios se ha medido la densidad, el coeficiente de dilatación térmica, la temperatura de transición vítrea y el índice de blancura. Los resultados indican que la opacificación que tiene lugar está directamente relacionada con la nucleación de microcristales y la separación de fases líquida. En los vidrios opacificados con $\mathrm{CaF}_{2}$ se produce la nucleación de microcristales de fluorita, mientras que en los opacificados con $\mathrm{P}_{2} \mathrm{O}_{5}$ tiene lugar un proceso combinado de nucleación de difosfato de silicio y silicato de calcio y de separación de fases. La opacificación inducida por $\mathrm{CaF}_{2}$ es más intensa que la que proporciona el $\mathrm{P}_{2} \mathrm{O}_{5}$, y adecuada para incorporar $\mathrm{Co}^{2+} \mathrm{a}$ fin de obtener una opalina de color azul.

๑ 2019 SECV. Publicado por Elsevier España, S.L.U. Este es un artículo Open Access bajo la licencia CC BY-NC-ND (http://creativecommons.org/licenses/by-nc-nd/4.0/).

\section{Opacification of crystal glass}

\section{A B S T R A C T}

Due to the historic, artistic and technological interest of opalinas from the Royal Glass Works of San Ildefonso (Spain), several opal glasses have been formulated in which $\mathrm{CaF}_{2}$ and $\mathrm{P}_{2} \mathrm{O}_{5}$ were the opacifiers. The objective is the obtaining of a composition that will be compatible with the production process of the National Glass Centre Foundation starting from the crystal glass commonly used for the historic pieces reproduction. The opal glasses obtained were characterized by visible spectrophotometry, X-ray diffraction, field emission scanning electron microscopy and dispersive X-ray microanalysis. Likewise, measurements of density, thermal expansion coefficient, glass transition temperature and whiteness index have been carried out. The results showed that opacification is directly connected with microcrystals nucleation and phase separation. In glasses containing $\mathrm{CaF}_{2}$ the nucleation

\footnotetext{
* Autor para correspondencia.

Correo electrónico: cgil@dce.uva.es (C. Gil). https://doi.org/10.1016/j.bsecv.2019.09.003

0366-3175/@ 2019 SECV. Publicado por Elsevier España, S.L.U. Este es un artículo Open Access bajo la licencia CC BY-NC-ND (http:// creativecommons.org/licenses/by-nc-nd/4.0/).
} 
t of fluorite microcrystals takes place, while in those opacified by $\mathrm{P}_{2} \mathrm{O}_{5}$ a combined process of silicon diphosphate/calcium silicate nucleation plus a phase separation occurs. The opacification induced by $\mathrm{CaF}_{2}$ is more intense that those of $\mathrm{P}_{2} \mathrm{O}_{5}$. Moreover, in the $\mathrm{CaF}_{2}$ containing composition the incorporation of $\mathrm{Co}^{2+}$ to obtain blue opalinas works correctly.

○ 2019 SECV. Published by Elsevier España, S.L.U. This is an open access article under the CC BY-NC-ND license (http://creativecommons.org/licenses/by-nc-nd/4.0/).

\section{Introducción}

Desde los tiempos más remotos de la historia del vidrio (Mesopotamia, tercer milenio antes de nuestra era) existen evidencias de los vidrios opales u opacos, es decir, vidrios parcialmente transparentes o prácticamente no transparentes. A pesar de la belleza o prestancia que tales vidrios podían presentar, la falta de transparencia no era una propiedad ni buscada ni intencionadamente provocada por los artesanos vidrieros, sino que era la simple consecuencia de la carencia de conocimientos técnicos, lo que impedía disponer de hornos y procesos de elaboración del vidrio que alcanzaran la temperatura necesaria para que las materias primas fundieran completamente y dieran lugar a un vidrio transparente [1]. Por ello puede decirse que desde la antigüedad existían los vidrios opales y opacos, si bien no eran más que el resultado de un procedimiento de obtención imperfecto, lo mismo que sus característicos tonos verdosos, causados fundamentalmente por las impurezas de hierro de las arenas aportadoras de la sílice, ya que no disponían de métodos de purificación de dichas materias primas. Aunque los tonos verdosos no eran intencionados, los vidrieros antiguos pronto adicionaron sales metálicas u otros componentes a la masa del vidrio con la finalidad de obtener vidrios coloreados.

Posteriormente la cultura egipcia fue una gran impulsora del vidrio y de la producción de objetos, en general de pequeño tamaño, de colores azul y verde mayoritariamente, que fue muy abundante. Casi todos los vidrios egipcios son opacos, independientemente de la funcionalidad del objeto: de mesa, joyas, ornamentos, etc., y también constituían artículos de lujo que imitaban las formas de otros contenedores realizados con otros materiales. Alrededor del 1100 antes de nuestra era aparecen algunas piezas de color blanco cremoso imitando con exactitud objetos realizados en alabastro. La gran variedad de colores constata que los egipcios ya dominaban las técnicas de coloración y que, aunque eran capaces de realizar vidrios algo translúcidos, en su mayoría seguían siendo opacos.

En el año 31 antes de nuestra era, tras la subida al poder de Augusto y la instauración del Imperio en Roma, se produjo en el mundo del vidrio la mayor innovación hasta el momento: la invención de la caña de soplar y la técnica del vidrio soplado. Con ella se aceleraron los ritmos productivos. La gran variedad de colores que se pueden observar en los objetos de esta época y la pureza que llegaron a alcanzar los vidrios romanos hacen pensar que los vidrieros dominaban las técnicas de coloración, decoloración y opacificación del vidrio [2]. La composición del vidrio romano y de periodos posteriores se mantuvo inalterada hasta el siglo xI. El cambio en la composición surgió porque la sosa, componente fundente de la masa vítrea, comenzó a escasear en Centroeuropa y los vidrieros de estas zonas sustituyeron este álcali por la potasa, que extraían de las cenizas de los helechos y de otras plantas de los bosques. De ahí que al vidrio de esta época se le denomine vidrio de bosque.

En el Renacimiento la supremacía de los vidrieros muraneses se extendió, lo mismo que el nuevo estilo clásico para todas las artes. En Murano se perfeccionó la calidad del vidrio y se creó el cristallo, que imitaba al cristal de roca (cuarzo). El cristallo era un vidrio de gran pureza y muy moldeable. Coetáneamente comenzaron a producir un vidrio, llamado lattimo o vidrio blanco de leche, que surgió como imitación de las delicadas y finas porcelanas orientales. El término blanco de leche deriva de la expresión francesa blanc de lait; en Inglaterra se denominaba milk glass, en Alemania Milchglas y en Italia lattimo. El término cristal blanco se utilizaba para el vidrio incoloro transparente y no para los vidrios opales u opacos. Tradicionalmente estos vidrios opales se elaboraban con la adición a la composición de cenizas de huesos calcinados, aunque los venecianos los conseguían agregando óxido de estaño [3]. La influencia de Murano en el vidrio europeo se prolongó hasta el siglo xviII, cuando los vidrieros de otras zonas comenzaron a ser más creativos y técnicamente avanzados. Estos fueron los casos de Inglaterra, con la invención del lead glass o vidrio al plomo, y de Bohemia, con el vidrio de base potásica [2].

En España la producción de objetos decorativos de vidrio blanco de leche en la Real Fábrica de Cristales de La Granja comenzó en las dos últimas décadas del sigloxviII, a raíz de la preferencia que se mostraba por este tipo de vidrio en Bohemia. Por entonces el vidrio blanco de leche se decoraba invariablemente con esmaltados que representaban escenas galantes, paisajes o ramos de flores, tratando de imitar la porcelana china y la alemana de Meissen. Generalmente esta decoración esmaltada de los vidrios opales solía combinarse con motivos dorados a fuego [4].

La llegada a La Granja en 1747 del maestro francés Dionisio Sibert determinó el comienzo de la producción de vidrio lechoso, como se denominó particularmente al vidrio opal en el Real Sitio, e inicialmente este vidrio blanco se utilizó para la elaboración de objetos que iban a ser decorados. En la Real Fábrica de Cristales se usaron distintos opacificantes para obtener el vidrio blanco de leche. En 1799 Facundo Díaz de Vargas y Argús explicaba los dos procedimientos extraídos de las recetas del libro Arte Vitraria [5]:

1. Según las fórmulas venecianas, por adición de cal de estaño y plomo.

2. Por mezcla de huesos o cuernos de ciervo calcinado (fosfato cálcico).

A pesar de que la producción de este tipo de vidrio fue abandonada antes de 1900, la variedad de artículos de vidrio 
opal que salió de la Real Fábrica de Cristales da cuenta de la magnitud e importancia que poseían, lo que, unido al gusto imperante entre los estratos sociales más favorecidos, explica que el vidrio opal fuera un elemento decorativo presente no solo en artículos de mesa, figuras, floreros y jarrones, sino también en tulipas, lámparas, espejos, cornucopias, servicios de tocador, de farmacia, etc. [6,7].

A principios del sigloxix los vidrios opales y opacos se colorean y adquieren importancia, sobre todo en Centroeuropa, con el descubrimiento de la hialita, que, semejante a la obsidiana, era un vidrio muy costoso de elaborar a partir de escorias; normalmente era de color negro, aunque también surgió una variante roja. Junto con la hialita comenzaron a aparecer vidrios que imitaban las piedras preciosas con una gran variedad de colores. Los primeros colores que aparecieron fueron el azul turquesa, amarillo y rosa, este último producido solo hasta 1840. A mediados del sigloxix los vidrios opales se fabricaron en una gama de colores vivos al estilo de los vidrios de Bohemia, y se produjeron con bases de vidrio cristal, semicristal y pâte de riz (vidrio obtenido por calentamiento en molde a partir de polvo fino de vidrio). Entre 1825 y 1830 se fabricaron opalinas con varios tonos de verde, y en 1828 la fábrica parisina de Bercy y la de Choisy-le-Roi realizaron una pequeña producción de opalinas púrpuras. El color azul cielo se inventó en Bohemia en 1835 y también se produjo en Francia hacia 1843 en las fábricas Baccarat y Saint-Louis. El color azul ultramar se usó muy frecuentemente entre 1845 y 1850, y en 1850 Baccarat produjo opalinas combinando azul y blanco. Estos vidrios se utilizaron primero para la fabricación de jarrones y frascos, sobre todo ornamentales, y más tarde también se realizó vidrio plano para vidrieras, con colores translúcidos veteados, muy apropiados para la realización de vidrieras naturalistas.

Paralelamente a los avances en el mundo del arte, también en el sigloxix se realizaron grandes avances técnicos y científicos, sobre todo en lo que a la óptica se refiere. Las investigaciones en este campo hicieron que fuese posible un mayor conocimiento de las propiedades de este material [1]. Y es también en esta época cuando se produce el mayor avance tecnológico desde la invención del vidrio soplado: el vidrio prensado a máquina. Esta primera mecanización supuso una producción a gran escala y obligó a emplear los grandes hornos de balsa [8]. Dichos avances hicieron posible la popularización definitiva del vidrio, y es donde comienza la diferenciación entre el vidrio mecanizado y utilitario, muy popular, y el vidrio artístico y artesanal, de marcado carácter ornamental.

La opacificación química del vidrio puede obtenerse mediante distintos procedimientos [8]:

a) Incorporación a la masa de vidrio de componentes cristalinos finamente divididos cuya temperatura de fusión es superior a la de formación del vidrio, y que poseen muy baja solubilidad en el vidrio fundido $\left(\mathrm{SnO}_{2}, \mathrm{TiO}_{2}, \mathrm{ZrO}_{2}, \mathrm{CeO}_{2}\right.$ y $\mathrm{Al}_{2} \mathrm{O}_{3}$ ).

b) Incorporación a la masa del vidrio de sustancias que reaccionan con algún componente de aquel formando microcristales (p.ej., fluoruros que dan lugar a la formación de cristales de fluoruros alcalinos y alcalinotérreos; o bien otros halogenuros, como cloruros, bromuros y yoduros). c) Formación de fases separadas debido a un proceso de inmiscibilidad líquida en el vidrio. Son vidrios opacificados con fosfatos [9], o también con arseniatos y antimoniatos, y vidrios opacificados con boratos. En estos vidrios, además de la presencia de microcristales de fosfatos o de boratos, se produce una dispersión de pequeñas gotitas enriquecidas en fosfatos o en boratos fundamentalmente de calcio.

d) Formación de fases separadas en vidrios ternarios de borosilicato sódico, borosilicato de plomo o borosilicato de cinc, en los que pequeñas adiciones de $\mathrm{TiO}_{2}$ o de $\mathrm{ZrO}_{2}$ favorecen la inmiscibilidad líquida.

Los vidrios opales históricos de la Real Fábrica de Cristales consistían en una matriz de vidrio de silicato sódico cálcico opacificado, bien a base de microcristales de óxido de estaño, o bien por una separación de fases debida a la presencia de fosfatos. Como es sabido, el vidrio actual de la Real Fábrica de Cristales es un vidrio con denominación comercial de vidrio sonoro superior (también denominado vidrio cristal) que contiene un $18 \%$ en peso de $\mathrm{PbO}$, de mejores propiedades y mayor calidad, desde el punto de vista ornamental y artístico, que el de silicato sódico cálcico. Debido a esta profunda diferencia composicional, se prevé que los procesos de opacificación sean distintos y, en consecuencia, es necesario un estudio de viabilidad para la correspondiente adaptación y optimización de los procedimientos que permiten obtener vidrios opales $u$ opacos de este tipo.

El principal objetivo del presente estudio consiste en la optimización del proceso de opacificación química del vidrio producido en la Fundación Centro Nacional del Vidrio, Real Fábrica de Cristales de La Granja. Desde el punto de vista estratégico en el sector de vidrio ornamental de alta calidad, los objetivos de este estudio se enfocan a la recuperación de la producción de objetos de vidrio opal (opalinas) característicos de la Real Fábrica de Cristales, cuya fabricación se abandonó aproximadamente a finales del siglo xIx, particularmente en lo que respecta a la producción de opalinas con matriz de vidrio con óxido de plomo, a diferencia de las clásicas que se fabricaron en siglos pasados, que se producían con vidrio común de silicato sódico cálcico. Con ello se podría ampliar la gama de artículos que se ofrece actualmente en la Fundación Centro Nacional del Vidrio y que son reproducción directa de los modelos históricos de la Real Fábrica de Cristales, pero mejorando la calidad intrínseca del vidrio opal.

\section{Parte experimental}

\section{Preparación de las muestras}

Como material de partida se ha utilizado un vidrio cristal sonoro superior incoloro comercial cuyas principales características se resumen en la tabla 1. Los datos de la composición química del vidrio de partida son los que facilita la empresa proveedora Glasma $A B$, oficialmente certificada con ISO 9001:2000 e ISO 14001. La información que se muestra indica el porcentaje máximo de los óxidos que lo componen.

Dicho vidrio sonoro superior se ajusta a las especificaciones que establece la norma UNE 43-603-79, sobre las 
Tabla 1 - Características del vidrio cristal sonoro superior utilizado como material de partida, según la empresa suministradora

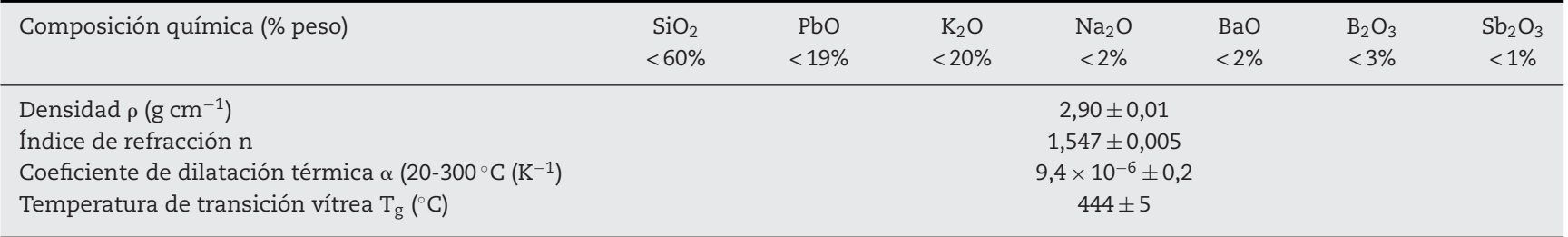

Tabla 2 - Características macroscópicas de los vidrios con aspecto opal u opaco obtenidos en las fusiones experimentales en función de las materias primas opacificantes y su proporción

\begin{tabular}{|c|c|c|c|c|}
\hline Muestra & Opacificante (\% peso) & Materia prima opacificante & Observación macroscópica & Imagen real \\
\hline 1 & $4 \mathrm{CaF}_{2}$ & $\mathrm{CaF}_{2}$ & No se produce opacificación & - \\
\hline 2 & $9 \mathrm{CaF}_{2}$ & $\mathrm{CaF}_{2}$ & La opacificación es casi completa & \\
\hline 3 & $15 \mathrm{CaF}_{2}$ & $\mathrm{CaF}_{2}$ & La opacificación es total & \\
\hline 4 & $7 \mathrm{P}_{2} \mathrm{O}_{5}$ & $\mathrm{Ca}_{3}\left(\mathrm{PO}_{4}\right)_{2}$ & $\begin{array}{l}\text { La opacificación solo alcanza un aspecto opal } \\
\text { translúcido }\end{array}$ & \\
\hline 5 & $15 \mathrm{CaF}_{2}(+0,02 \mathrm{CoO})$ & $\mathrm{CaF}_{2}$ & La opacificación es total, color azul & \\
\hline
\end{tabular}

denominaciones de los distintos tipos de vidrios [10]. Con él se prepararon por fusión convencional diversas muestras adicionando diferentes proporciones de compuestos opacificantes (tabla 2).

Puesto que la capacidad opacificante de los iones $\mathrm{F}^{-}$es mayor que la de los fosfatos, se formularon tres composiciones con diversas proporciones de $\mathrm{CaF}_{2}$ y solo una con $\mathrm{P}_{2} \mathrm{O}_{5}$ $[8,9]$. Adicionalmente se preparó un vidrio azul coloreado con iones $\mathrm{Co}^{2+}$ y opacificado con $\mathrm{CaF}_{2}$.

Las fusiones experimentales se realizaron en un horno eléctrico Termiber para ensayos de laboratorio. La mezcla vitrificable preparada para obtener $150 \mathrm{~g}$ de vidrio final se fundió en crisoles de mullita-alúmina hasta alcanzar una temperatura de $1.550^{\circ} \mathrm{C}$, con una curva de fusión programada de $10,5 \mathrm{~h}$, incluida la bajada de temperatura hasta unos $50^{\circ} \mathrm{C}$. Los detalles de la curva de fusión en la que se producen las diferentes etapas del proceso de fusión fueron los siguientes:

- Tramo I. Temperatura alcanzada $\left(\mathrm{T}_{\mathrm{f}}\right)=600^{\circ} \mathrm{C}$; velocidad de calentamiento $\left(v_{c}\right)=9,7^{\circ} \mathrm{C} / \mathrm{min}$.

- Tramo II. $\mathrm{T}_{\mathrm{f}}=900^{\circ} \mathrm{C} ; \mathrm{v}_{\mathrm{C}}=6^{\circ} \mathrm{C} / \mathrm{min}$.

- Tramo III. $\mathrm{T}_{\mathrm{f}}=1.500^{\circ} \mathrm{C} ; \mathrm{v}_{\mathrm{C}}=9^{\circ} \mathrm{C} / \mathrm{min}$.
- Tramo IV. $\mathrm{T}_{\mathrm{f}}=1.500^{\circ} \mathrm{C} ; \mathrm{t}=120 \mathrm{~min}$ (meseta).

- Tramo V. $\mathrm{T}_{\mathrm{f}}=1.550^{\circ} \mathrm{C} ; \mathrm{v}_{\mathrm{C}}=0,8^{\circ} \mathrm{C} / \mathrm{min}$.

- Tramo VI. $\mathrm{T}_{\mathrm{f}}=1.550^{\circ} \mathrm{C} ; \mathrm{t}=48 \mathrm{~min}$ (meseta en la que se realiza el colado de vidrio).

- Tramo VII. $\mathrm{T}_{\mathrm{f}}=1.000^{\circ} \mathrm{C}$; velocidad de enfriamiento $\left(\mathrm{v}_{\mathrm{e}}\right)=9,2^{\circ} \mathrm{C} / \mathrm{min}$.

- Tramo VIII. $\mathrm{T}_{\mathrm{f}}=50^{\circ} \mathrm{C} ; \mathrm{v}_{\mathrm{e}}=15,8^{\circ} \mathrm{C} / \mathrm{min}$.

Una vez fundidos los vidrios, se colaron sobre un molde de latón para obtener lingotes prismáticos con unas dimensiones aproximadas de $70 \times 30 \times 12 \mathrm{~mm}$. Estos lingotes se recocieron posteriormente de acuerdo con un programa de enfriamiento lento y controlado con el fin de garantizar la relajación de su estructura y evitar la aparición de tensiones residuales. El cálculo de la curva de recocido se realizó según el procedimiento de la empresa Corning Inc. ${ }^{\circledR}$ (Corning, Nueva York, EE.UU.), que considera las temperaturas inferior y superior de recocido ( 430 y $480^{\circ} \mathrm{C}$, respectivamente), el espesor de la muestra $(1,2 \mathrm{~cm})$, el coeficiente de dilatación térmica $\left(9,4 \times 10^{-6} \mathrm{~K}^{-1}\right) \mathrm{y}$ la temperatura ambiente final $\left(20^{\circ} \mathrm{C}\right)$. Este procedimiento es coincidente con el de la norma [10] y se especifica en [8]. Los detalles de la curva de recocido fueron los siguientes: 
- Etapa I. $\mathrm{T}_{\mathrm{f}}=485^{\circ} \mathrm{C} ; \mathrm{t}=30,6 \mathrm{~min}$ (meseta).

- Etapa II. $\mathrm{T}_{\mathrm{f}}=411^{\circ} \mathrm{C} ; \mathrm{v}_{\mathrm{e}}=0,7^{\circ} \mathrm{C} / \mathrm{min}$.

- Etapa III. $\mathrm{T}_{\mathrm{f}}=361^{\circ} \mathrm{C} ; \mathrm{v}_{\mathrm{e}}=0,4^{\circ} \mathrm{C} / \mathrm{min}$.

- Etapa IV. $\mathrm{T}_{\mathrm{f}}=1550^{\circ} \mathrm{C} ; \mathrm{v}_{\mathrm{e}}=2,2^{\circ} \mathrm{C} / \mathrm{min}$.

Mediante cortes transversales de los lingotes obtenidos se prepararon láminas de $\approx 2 \mathrm{~mm}$ de espesor. Dichas láminas se sometieron por ambas caras a un proceso previo de desbaste con lijas de carburo de silicio de diferentes tamaños de grano, y por último a un pulido con una suspensión acuosa de óxido de cerio. Así se obtuvieron superficies planoparalelas pulidas a espejo por ambas caras de las características requeridas para poder realizar correctamente el estudio de su transmisión óptica.

\section{Caracterización de las muestras}

Las medidas de densidad se realizaron según el procedimiento de determinación del empuje hidrostático que experimenta la muestra al sumergirla en un líquido de densidad conocida (bromoformo, $\rho=2,826 \mathrm{~g} \mathrm{~cm}^{-3}$ ). Se utilizó una balanza analítica AND-ER de precisión $\pm 0,0001 \mathrm{~g}$.

Los coeficientes de dilatación térmica lineal y las temperaturas de transición vítrea de las muestras se determinaron a partir de las curvas dilatométricas registradas con un dilatómetro diferencial Netzsch modelo 402 EP. Para ello se usaron muestras paralelepipédicas de los vidrios de aproximadamente $5 \mathrm{~mm}$ de espesor.

La opalescencia u opacidad de los vidrios se evaluó por espectrofotometría de transmisión óptica en el intervalo de longitud de onda de 320-780 nm. Los espectros se registraron con un espectrofotómetro Perkin Elmer UV/VIS/NIR Lambda 19 utilizando las láminas pulidas a espejo por ambas caras. El índice de blancura se estimó sobre la superficie de las muestras. Las medidas se realizaron con un colorímetro portátil Metrotec modelo Blue Line CM-310, en modo reflectancia con iluminante D65 y ángulo de visión de $10^{\circ}$. Para la calibración se utilizaron patrones internos suministrados por Metrotec, que consisten en un patrón negro para $0 \%$ de transmitancia y un patrón blanco para $100 \%$ de transmitancia. Dichos patrones se utilizaron también como fondos de referencia durante las medidas. Se llevaron a cabo tres medidas por muestra y se calculó su correspondiente promedio.

El estudio de las fases microcristalinas formadas se llevó a cabo mediante difracción de rayos X (DRX) con un difractómetro Panalytical X'Pert Modelo MPD, utilizando la radiación $\mathrm{K} \alpha$ del cobre (1,54056 ̊), bajo condiciones de trabajo de $45 \mathrm{kV}$ y $40 \mathrm{~mA}$. Los difractogramas se registraron entre $2 \theta=5-60^{\circ} \mathrm{a}$ partir de muestra en polvo molida en mortero de ágata hasta un tamaño de grano inferior a $30 \mu \mathrm{m}$.

La microestructura de los vidrios se observó por microscopia electrónica de barrido de emisión de campo (MEBEC) con un equipo de cátodo frío Hitachi S-4800, trabajando con tensiones de aceleración de $15 \mathrm{kV}$. Los microanálisis de espectrometría de dispersión de energías de rayos X (EDS) se realizaron con un sistema acoplado al microscopio Oxford $\mathrm{X}$-Max de $20 \mathrm{~mm}^{2}$ con resolución de $125 \mathrm{eV}(\mathrm{Mg} \mathrm{K} \alpha)$. Las muestras se prepararon mediante fractura fresca realizada en un mortero de ágata. A continuación se llevó a cabo un ataque superficial con vapores de HF durante 10-30 s, seguido de varios lavados con agua destilada y secado para garantizar la total eliminación de iones fluoruro procedentes del HF en las muestras. Posteriormente las muestras se recubrieron con carbono como medio conductor mediante vaporización en un equipo JEOL JEE4b.

Todos los vidrios de la tabla 2 se seleccionaron para su caracterización mediante densitometría y espectrofotometría visible, y además, en los que presentan mayor grado de opacificación se llevó a cabo un estudio más detallado por dilatometría, DRX y MEBEC-EDS. Adicionalmente, para evaluar como viables los vidrios obtenidos se tuvieron en cuenta parámetros cualitativos experimentales de fusión, como la viscosidad a la temperatura de colado, la corrosión producida en el crisol por el agente opacificante y la cantidad mínima necesaria de agente opacificante.

\section{Resultados y discusión}

\section{Fusiones experimentales}

La observación cualitativa de los vidrios obtenidos en las fusiones experimentales indicó que la naturaleza y el porcentaje del opacificante determinan su grado de opalescencia, siendo ésta más intensa para mayores proporciones de opacificante. Así la muestra 1 que contiene la menor cantidad de $\mathrm{CaF}_{2}$ no presentó aspecto opal, sino transparente incoloro por lo que se descartó el porcentaje de $4 \%$ de dicho fluoruro como posible agente opacificante. En la tabla 2 se observa el aspecto visual de los vidrios obtenidos en las fusiones experimentales que presentan un grado de opacificación notable.

\section{Medidas de densidad y propiedades térmicas}

En la tabla 3 se indican los resultados de las medidas de densidad $(\rho)$ de los vidrios opales u opacos seleccionados, así como la del vidrio sonoro de partida. De acuerdo con la norma UNE 43-603-79 [10], la densidad de un vidrio con denominación sonoro superior ha de ser igual o superior a $2,45 \mathrm{~g} \mathrm{~cm}^{-3}$. Por lo tanto, todas las muestras seleccionadas cumplen dicha norma y, además, su valor de densidad se encuentra muy próximo al del vidrio sonoro superior de partida, lo que garantiza la calidad requerida.

Los coeficientes de dilatación térmica lineal $(\alpha)$ y las temperaturas de transición vítrea $\left(\mathrm{T}_{\mathrm{g}}\right)$ se determinaron a partir de las correspondientes curvas dilatométricas, siguiendo la norma UNE-43-703-78 [11]. La tabla 3 recoge dichos resultados para dos muestras tipo, una opacificada con fluoruros y otra con fosfatos, así como para el vidrio sonoro de partida. Estos resultados indican que, a pesar de que los valores de $\alpha$ y $\mathrm{T}_{\mathrm{g}}$ difieren de los del vidrio sonoro de partida, los vidrios opales formulados y obtenidos son adecuados para la fabricación manual por soplado de objetos según el procedimiento habitual de la Fundación Centro Nacional el Vidrio para la reproducción de piezas históricas de la Real Fábrica de Cristales.

\section{Análisis espectrofotométrico y de DRX}

El registro de los espectros visibles en modo transmitancia de las muestras de la tabla 2 indicó que para estos vidrios opa- 
Tabla 3 - Propiedades de los vidrios estudiados

\begin{tabular}{llccc} 
Muestra & Densidad $\left(\mathrm{g} \mathrm{cm}^{-3}\right)$ & $\alpha \cdot 10^{-7}\left(\mathrm{~K}^{-1}\right)$ & $\mathrm{T}_{\mathrm{g}}\left({ }^{0} \mathrm{C}\right)$ & Índice de blancura promedio \\
\hline 2 & 2,81 & 93,0 & 450,0 & 73,38 \\
3 y 5 & 2,79 & 73,0 & 520,3 & 88,56 \\
4 & 2,87 & 102,0 & 493,0 & 51,64 \\
Sonoro & 94,0 & 444,0 & - \\
\hline
\end{tabular}

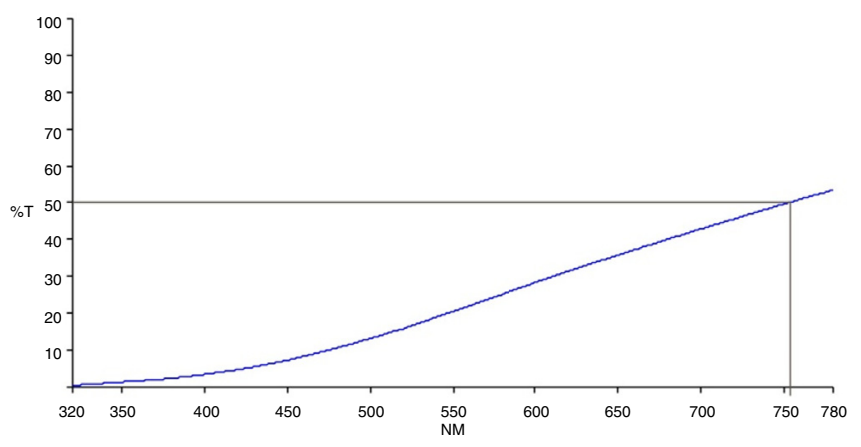

Figura 1 - Espectro de transmitancia de la muestra 4 en el intervalo visible.

les u opacos la transmitancia teórica es cero, excepto para el vidrio 4, cuyo espectro se muestra en la figura 1. Como se puede observar para la muestra 4 , que contiene $7 \%$ en peso de $\mathrm{P}_{2} \mathrm{O}_{5}$ y presenta el menor grado de opacificación del conjunto de los vidrios estudiados, la transmitancia no supera el $60 \%$ y su borde de absorción se sitúa a $755 \mathrm{~nm}$ aproximadamente. En las otras muestras que presentan opacificación intensa o total se comprobó que el valor de la transmitancia es cero a lo largo de todo el intervalo visible.

La tabla 3 recoge los valores estimados de índice de blancura de las muestras blancas u opales. Los resultados obtenidos son coherentes con la apreciación visual del grado de opacificación de las muestras. Así, la muestra 3, que contiene un $15 \%$ en peso de $\mathrm{CaF}_{2}$, es la que presenta el mayor índice de blancura, mientras que la muestra 2, que contiene un $9 \%$ en peso de dicho opacificante, tiene un índice de blancura más de diez unidades menor. Por otro lado, la muestra 4, opacificada con un $7 \%$ en peso de $\mathrm{P}_{2} \mathrm{O}_{5}$, solo alcanza un 51,64 de índice de blancura, lo que se correlaciona con su aspecto opal traslúcido y, por tanto, menos blanco.

Los difractogramas de rayos $\mathrm{X}$ correspondientes a las muestras 3 y 4 (fig. 2) indican las fases cristalinas inducidas por los agentes opacificantes en los vidrios durante su proceso de fusión y recocido. En el difractograma de la muestra 3 (fig. 2a) se identificó una sola fase correspondiente a fluorita $\left(\mathrm{CaF}_{2}\right)$. Aparecen bien definidas sus tres reflexiones principales y presenta un grado de cristalinidad notable, lo que indica que dicha fase se encuentra desarrollada en la muestra 3. También se identificó el hombro característico que presentan los vidrios de silicato entre $2 \theta=20-35^{\circ}$, aproximadamente, y que se corresponde con la sílice amorfa.

En el difractograma de la muestra 2 (fig. 2b) solo se detectaron dos fases de formación incipiente, según se aprecia por su bajo grado de cristalinidad. Estas fases son un difosfato de silicio $\mathrm{Si}\left(\mathrm{P}_{2} \mathrm{O}_{7}\right)$ y un silicato de calcio $\mathrm{Ca}_{2} \mathrm{SiO}_{4}$. El hombro característico de la sílice en los vidrios de silicato, que se solapa con las reflexiones de las fases anteriores, impide la identificación de otras posibles fases cristalinas. No obstante, teniendo en cuenta las reflexiones principales que aparecen a $2 \theta=30-35^{\circ}$, no se descarta totalmente la posibilidad de un crecimiento incipiente de hidroxiapatita, fosfato de calcio hidratado $\left[\mathrm{Ca}_{5}\left(\mathrm{PO}_{4}\right)_{3}(\mathrm{OH})\right]$.

El hecho de que la muestra 4 presente un aspecto netamente opal y que, sin embargo, las fases cristalinas que en ella se identifican sean de muy baja cristalinidad o desarrollo, indica que no se puede descartar que, además de dichas fases incipientes, exista un fenómeno de separación de fases que contribuya a su opalescencia. Como ya se ha indicado anteriormente en el apartado1, el mecanismo de opacificación mediante la generación de fases separadas por un fenómeno de inmiscibilidad líquida en el seno del vidrio es un proceso frecuente en vidrios de silicofosfato [8].
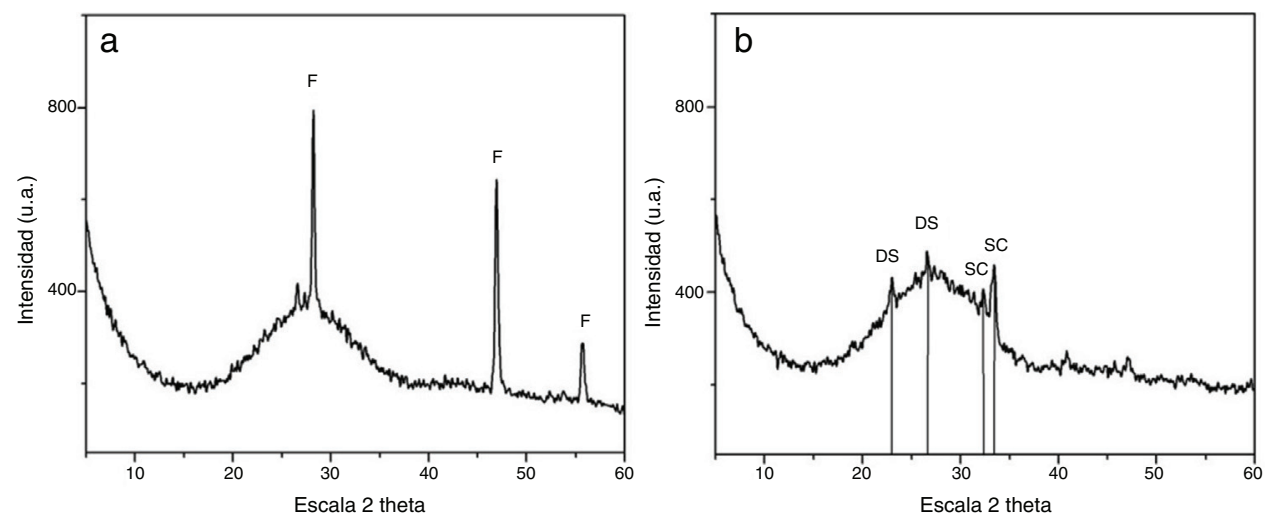

Figura 2 - Difractogramas de rayos X: a) muestra 3; b) muestra 4. F: fluorita $\mathrm{CaF}_{2}$; DS: difosfato de silicio $\mathrm{Si}\left(\mathrm{P}_{2} \mathrm{O}_{7}\right)$; $\mathrm{SC}$ : silicato de calcio $\mathrm{Ca}_{2} \mathrm{SiO}_{4}$. 


\section{Observaciones de MEBEC y microanálisis EDS}

En la figura 3 se muestran micrografías de MEBEC del vidrio 2 que contiene $9 \%$ en peso de $\mathrm{CaF}_{2}$.

La microestructura de fondo (fig. 3a) presenta una textura profusa de granos de un tamaño de diámetro aproximado de $0,2 \mu \mathrm{m}$ (fig. 3b). Además se observan formas de tono claro dispersas que pueden atribuirse o bien a depósitos de pequeños fragmentos del vidrio generados durante la preparación de la muestra (fractura fresca del vidrio) o bien a una nucleación incipiente. Los microanálisis EDS efectuados en una zona del fondo granular indican un contenido de $\mathrm{F}^{-}$alrededor de un $5 \%$ en peso, mientras que en uno de los granos blancos de mayor tamaño $\left(\approx 3,5 \mu \mathrm{m}\right.$ ) el porcentaje de $\mathrm{F}^{-}$sobrepasa el $34 \%$ en peso. Este resultado indica que es más probable que las formas blancas sean pequeños núcleos cristalinos de $\mathrm{CaF}_{2}$. Texturalmente la parte más superficial de la muestra (fig. 3c) presenta una costra de aspecto heterogéneo (fig. 3d), bajo la cual aparece una microestructura caracterizada por huecos de forma esférica o globular (fig. 3e). En ella, una parte considerable de los granos se han arrancado (probablemente por efecto del ataque con vapores de HF), dejando en su lugar huecos que confieren un aspecto poroso. Los resultados de los microanálisis EDS realizados en la zona de costra y en la zona por debajo de la costra indicaron que los contenidos de $\mathrm{F}^{-}$se sitúan alrededor del 34 y del 9\% en peso, respectivamente. Es decir, en la zona por debajo de la costra con una textura dominada por huecos es posible que gran parte de los núcleos cristalinos de $\mathrm{CaF}_{2}$ se hayan lixiviado en el ataque en medio ácido, y que dicho ataque se haya producido de forma diferencial dejando áreas más o menos atacadas que explican la presencia de la costra que se observa en la figura 3c. Además, este hecho explicaría la forma globular de los huecos en la zona por debajo de la costra (fig. 3e).

Las imágenes de MEBEC de la muestra 3 que contiene un $15 \%$ en peso de $\mathrm{CaF}_{2}$ se presentan en la figura 4.

La microestructura de esta muestra consiste en grandes áreas o gotas de fina textura rugosa, inmersas en una matriz también rugosa de grano más amplio. Ambas texturas, independientemente de su grado de rugosidad, son homogéneas e indican que pueden ser el resultado de una inmiscibilidad líquida o separación de fases. Este fenómeno es común en los
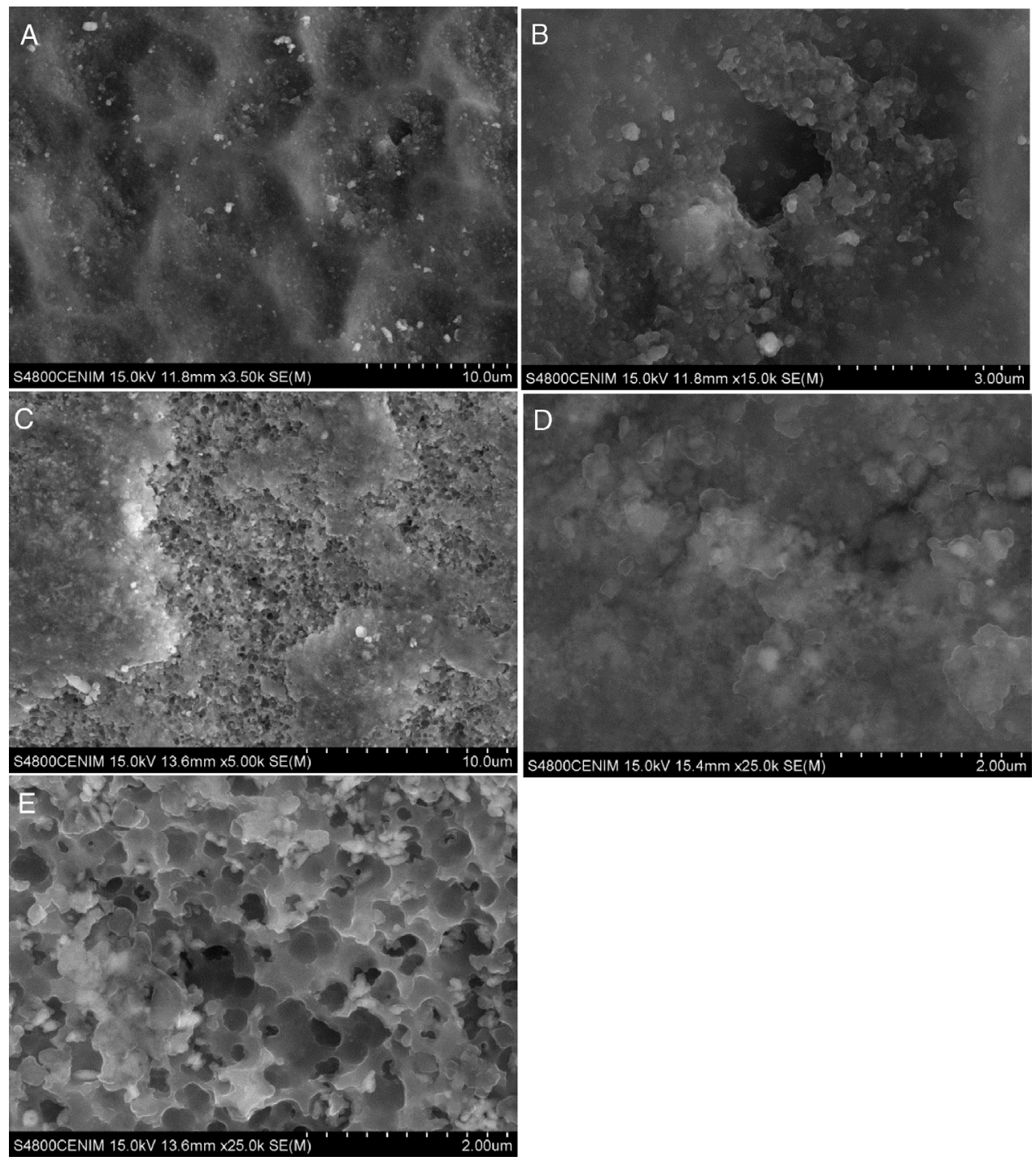

Figura 3 - Imágenes de MEBEC de la muestra 2 ( $9 \%$ en peso $\left.\mathrm{CaF}_{2}\right)$. 

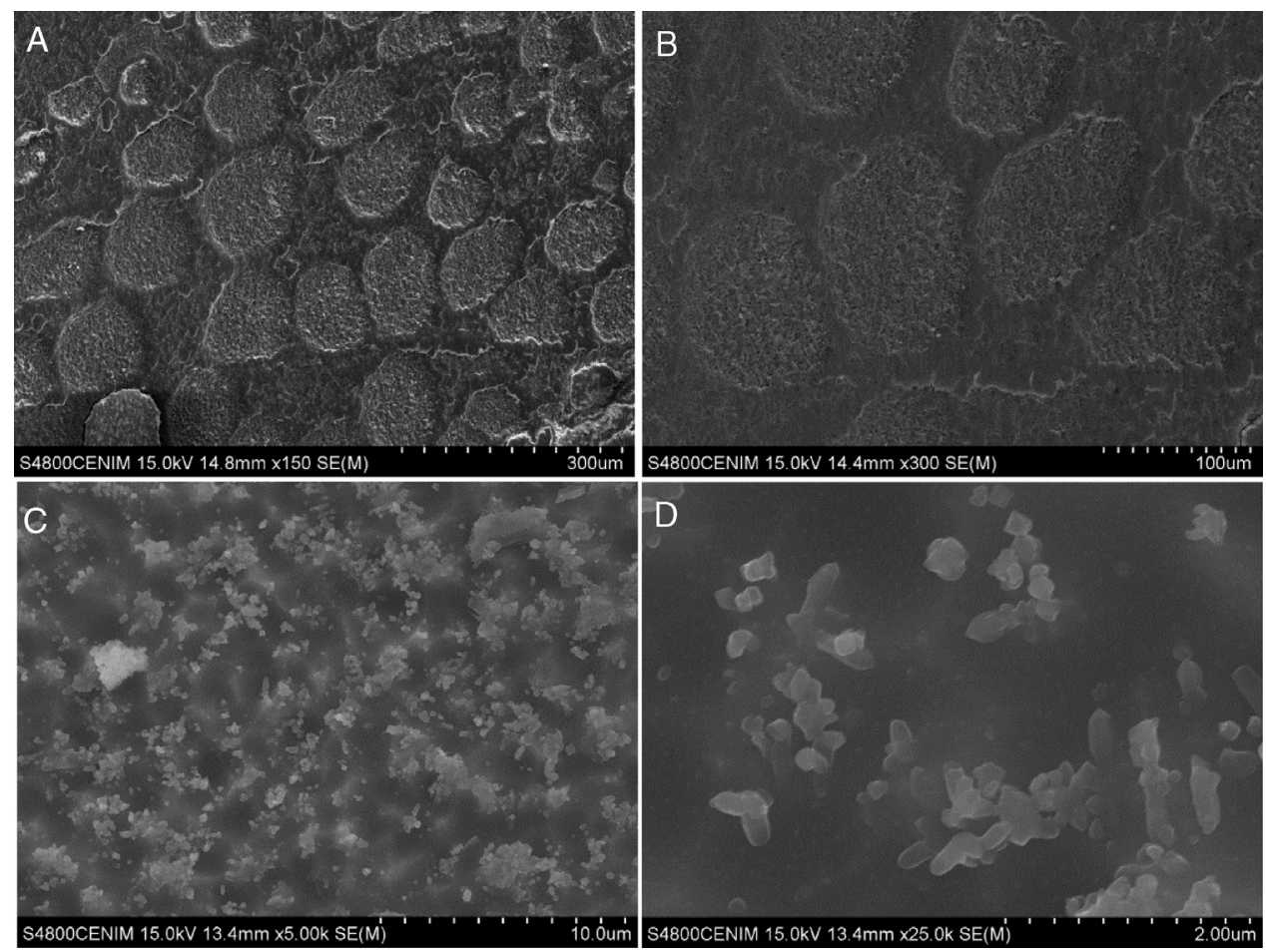

Figura 4 - Imágenes de MEBEC de la muestra $3\left(15 \%\right.$ en peso $\left.\mathrm{CaF}_{2}\right)$.

vidrios de fluoruro [8], y es conocido el hecho de que la incorporación de iones $\mathrm{F}^{-}$favorece notablemente la inmiscibilidad líquida en diversos sistemas de composiciones de vidrios, lo que provoca su separación de fases [12]. En los vidrios separados la fase que posee una mayor tensión superficial se segrega de la otra formando pequeñas gotas que pueden quedar aisladas o bien interconectarse, de modo que cuando el vidrio se enfría las dos fases líquidas quedan congeladas formando un vidrio con dos fases separadas. Cuando el tamaño de esas gotas es grande y los índices de refracción de las dos fases son distintos, tiene lugar la opalescencia, e incluso la opacificación en el caso más extremo. En el caso del vidrio 3 el tamaño promedio del diámetro de las gotas es de unos $120 \mu \mathrm{m}$. Los microanálisis de EDS realizados en diversas zonas dentro de las grandes gotas y fuera de ellas, en lo que se podría considerar la matriz, indicaron que el contenido en peso de flúor es del mismo orden de magnitud.

A mayores aumentos la textura guarda ciertas similitudes con la observada en la muestra 2 (con $9 \%$ en peso $\mathrm{CaF}_{2}$ ) pero con un aspecto granular más acusado. Aparecen zonas más heterogéneas donde coexisten formas de tamaños diversos (fig. 4c), aunque se mantiene un fondo dominado por una fina estructura de granos. Algunos de esos granos muestran aristas incipientes (fig. 4d), lo que apunta a una nucleación cristalina. Los microanálisis EDS realizados por duplicado en distintas áreas (granos grandes, acumulación de granos pequeños y zona de fondo) pusieron de manifiesto que las concentraciones de $\mathrm{F}^{-}$varían notablemente. En los granos grandes, como la forma blanca que aparece en la figura 4c, el porcentaje de $\mathrm{F}^{-}$varió entre el 36 y el $44 \%$ en peso. En las zonas donde se observa una profusión de granos pequeños, por ejemplo las formas claras de la figura $4 d$, el contenido aproximado de $\mathrm{F}^{-}$es del $19 \%$ en peso. El fondo oscuro que presenta los granos más sutiles (fig. 4c,d) contiene de un 4 a un $6 \%$ en peso de $\mathrm{F}^{-}$. Estos resultados confirman que todas las formas granulares observadas, independientemente de su tamaño, de su profusión y de que aparezcan como textura de fondo o como elementos destacados de dicho fondo, pueden atribuirse a una nucleación de microcristales de $\mathrm{CaF}_{2}$.

En la figura 5 se muestran las imágenes de MEBEC del vidrio 4.

La muestra 4 , que contiene un $7 \%$ de $\mathrm{P}_{2} \mathrm{O}_{5}$, presenta la microestructura homogénea que se observa en la figura $5 \mathrm{a}$, con una textura de ondas profusas y aplanadas de bordes redondeados (fig. 5b). Las ondas redondeadas se encuentran superpuestas e interconectadas y no muestran rugosidad sino un aspecto liso. Esta microestructura puede ser el resultado de una separación de fases líquida de tipo espinodal [8] en la que las gotas más pequeñas de la fase inicialmente dispersa se disuelven haciendo aumentar de tamaño a las más grandes. En este caso se puede generar una fase nueva sin ninguna barrera energética, las variaciones composicionales pueden tener lugar y, consecuentemente, la fase se separa en muy poco tiempo mediante un proceso de difusión [13]. Hay que señalar que en esta muestra no se observan formas con aristas que en principio pudieran sugerir algún tipo de nucleación de microcristales, o bien que son tan pequeños que escapan al límite de resolución del microscopio electrónico utilizado. Puesto que los resultados de DRX del vidrio 4 demostraron la existencia de difosfato de silicio $\mathrm{Si}\left(\mathrm{P}_{2} \mathrm{O}_{7}\right)$ y de silicato de calcio $\mathrm{Ca}_{2} \mathrm{SiO}_{4}$ como fases de formación incipiente con bajo grado de cristalinidad, queda claro que dichas fases cristalinas son escasas y que sus tamaños se encuentran fuera del límite de resolución del microscopio con las condiciones 


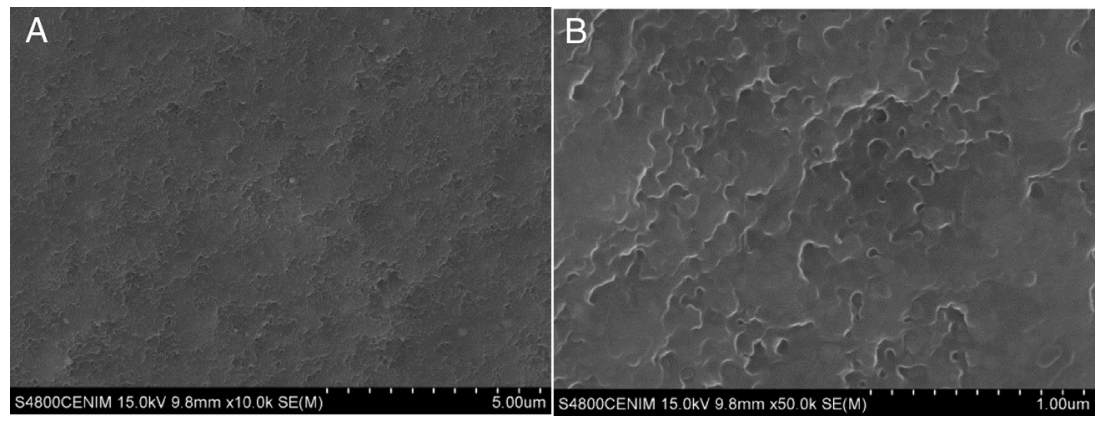

Figura 5 - Imágenes de MEBEC de la muestra $4\left(7 \%\right.$ en peso $\left.\mathrm{P}_{2} \mathrm{O}_{5}\right)$.

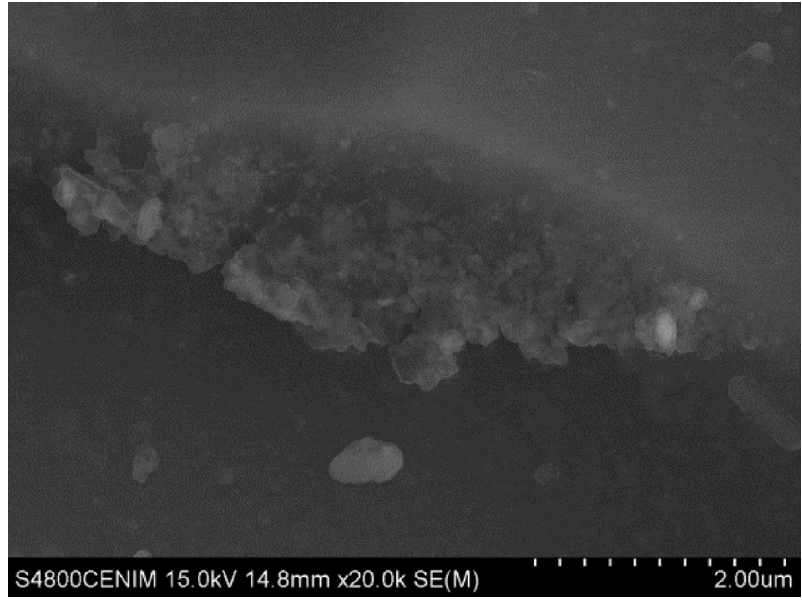

Figura 6 - Imagen de MEBEC de la muestra 5 (color azul, $15 \%$ en peso $\mathrm{CaF}_{2}$ ).

de trabajo consignadas en el apartado «Caracterización de las muestras». Por lo tanto, en la muestra 4 la opacidad (en realidad un aspecto opalescente) se debe no solo a la presencia de pequeños núcleos cristalinos de difosfato de silicio y silicato de calcio, sino a la coexistencia de dichos núcleos con una profusa separación de fases líquida. El microanálisis cualitativo EDS del fondo indica que el porcentaje promedio de fósforo es de un $2 \%$ en peso. Sin embargo, este resultado no es completamente fiable, ya que las fases enriquecidas en fósforo pueden haberse lixiviado por acción de los vapores de HF durante la preparación de la muestra.

La muestra 5 (de color azul), que, al igual que la muestra 3 , contiene un $15 \%$ en peso $\mathrm{CaF}_{2}$, presenta una microestructura semejante a esta con textura granular y pequeñas formas con aristas incipientes (fig. 6). Dichas formas se atribuyen a núcleos cristalinos de $\mathrm{CaF}_{2}$. La textura del fondo es homogénea, algo rugosa y de aspecto difuso.

\section{Comparación del resultado de los agentes opacificantes utilizados}

Desde finales del sigloxix el uso de fluoruros es el procedimiento utilizado industrialmente como opacificante. La opacificación se debe, como es sabido, a la generación desde el vidrio fundido de microcristales de fluoruros alcalinos y alcalinotérreos, fundamentalmente. En realidad dicha generación de microcristales tiene lugar después de que se produzca una separación de fases inducida por los iones $\mathrm{F}^{-}$, que se incorporan a la red vítrea en las posiciones de los iones oxígeno. De este modo se destruyen los puentes de oxígeno y la discontinuidad que esto provoca hace disminuir localmente la tensión superficial. Se crean zonas de distinta composición, unas enriquecidas en sílice y otras en fluoruro, que terminan formando dos fases inmiscibles, para finalizar con la evolución de una de ellas a microcristales de un tamaño comprendido entre 300 y $900 \mathrm{~nm}$ en los vidrios opales de mejor aspecto.

En cuanto a los vidrios opacificados con fosfatos (procedimiento conocido por los vidrieros de Venecia desde el sigloxvi), el $\mathrm{P}_{2} \mathrm{O}_{5}$ se incorpora como unidades tetraédricas $\left[\mathrm{PO}_{4}\right]$ alternadas con las unidades $\left[\mathrm{SiO}_{4}\right]$, de modo que los iones $\mathrm{P}^{5+}$ se unen con un doble enlace a uno de los cuatro átomos de oxígeno de la unidad $\left[\mathrm{PO}_{4}\right]$. Este átomo de oxígeno deja, por tanto, de ser un puente entre dos unidades y actúa como terminal en la red vítrea, al que se aproximan otros iones modificadores. El resultado es que se producen ligeros cambios composicionales locales que determinan un aumento de la tensión interfacial, con la consiguiente separación de fases y opacificación. También es conocido el caso de vidrios de fosfato en los que coexiste la separación de fases con la aparición de fases cristalinas, frecuentemente de fosfatos de calcio [14-16].

La opacificación de los vidrios con fosfatos presenta la ventaja de carecer de efectos tóxicos y no contaminar el ambiente en los centros de producción. Otra ventaja es que los fosfatos se volatilizan menos que los fluoruros durante la fusión del vidrio. Respecto a su acción corrosiva en los crisoles, tanto la acción de los fluoruros como la de los fosfatos son elevadas, aunque es aún mayor en el caso de los fluoruros. Desde el punto de vista económico y de viabilidad de producción, el coste de los vidrios opales de fosfato es mayor que el de los de fluoruro. Los vidrios de fosfato presentan comparativamente menor grado de opacidad que los de fluoruro; de hecho, los vidrios de fosfato son más translúcidos (más opales) y deben conformarse en masa para poder alcanzar espesores relativamente elevados que potencien su aspecto opaco [8].

\section{Conclusiones}

Todas las muestras seleccionadas como posibles vidrios sonoros superiores opales u opacos cumplen las especificaciones 
de la norma correspondiente que los define como tales. Por lo tanto, se ha alcanzado el objetivo de formular y preparar nuevos vidrios sonoros opales u opacos de fácil implantación en el habitual proceso de fabricación de la Fundación Centro Nacional del Vidrio, con la consiguiente innovación que ello puede suponer desde el punto de vista comercial. En cuanto a la posibilidad de obtener vidrios sonoros opales coloreados, se ha preparado un vidrio opaco azul con resultados muy satisfactorios, con lo que se amplía la gama de vidrios tanto opales como de color.

La opacificación de las muestras estudiadas debe atribuirse principalmente a la presencia de las fases microcristalinas dispersas detectadas por DRX y/o a la separación de fases líquida, dependiendo de la composición de los vidrios en cuanto al opacificante que contienen. Es decir, los vidrios en los que se usó $\mathrm{CaF}_{2}$ la opacificación es debida a la nucleación de microcristales de fluorita, mientras que en los vidrios que contienen $\mathrm{P}_{2} \mathrm{O}_{5}$ el mecanismo de opacificación es el resultado de la acción conjunta de la nucleación de cristales submicroscópicos de difosfato de silicio y silicato de calcio y de una separación de fases líquido-líquido. La relación opacificación-cristalinidad queda bien reflejada en el hecho de que el vidrio con aspecto opaco más puro es el que presenta reflexiones más intensas y mejor resueltas en el correspondiente difractograma de rayos X. Por otro lado, la relación opacificación-separación de fases es también directa, pero la calidad de la opacificación se intensifica por la presencia conjunta de núcleos cristalinos. Sin embargo, en este caso no se alcanza el grado de opacificación que se produce en los vidrios que contienen un porcentaje considerable de microcristales bien formados.

A la vista de los resultados obtenidos, las composiciones recomendables para la producción de objetos de vidrio opal (opalinas) característicos de la Real Fábrica de Cristales son la de la muestra 3 (opalinas opacas blancas) y 5 (opalinas opacas azules), mientras que la composición de la muestra 4 sería adecuada para la fabricación de opalinas traslúcidas.

\section{Agradecimientos}

Los autores agradecen a la Fundación Centro Nacional del Vidrio las facilidades prestadas para la consecución parcial de la parte experimental. Asimismo, agradecen la financiación parcial del programa TOP Heritage (Comunidad de Madrid, P2018/NMT-4372), y el apoyo profesional de TechnoHeritage, Red de Ciencia y Tecnología para la Conservación del Patrimonio Cultural, y de la Plataforma Temática Interdisciplinar del CSIC, Patrimonio Abierto: Investigación y Sociedad (PTI-PAIS).

\section{B I B L I O G R A F Í A}

[1] M. García Heras, J.M. Fernández Navarro, M.A. Villegas, Historia del Vidrio, CSIC, Madrid, 2012.

[2] H. Tait, Five Thousand Years of Glass, British Museum Press, London, 1991.

[3] Wilson, Charles West. Westmoreland's Opal Formulations. As Found in Brainard West's Notebook. Opaque News, Sep. 1993), s.p. Disponible en: http://www.nmgcs.org/.16/12/ 09.

[4] P. Pastor Rey de Viñas, La Real Fábrica de Cristales de La Granja, Arte Segovia, Segovia, 1998.

[5] A. Neri, De Arte Vitraria, 1686, Trad. Miguel Suárez.

[6] L. Pérez Bueno, Vidrio, en: F. Carreras CAndi (Ed.), Folklore y costumbres de España, Alberto Martín, Barcelona, 1931.

[7] A. Wilson Frothingham, Hispanic Glass, Hispanic Society of America, New York, 1941.

[8] J.M. Fernández Navarro, Vidrio, Consejo Superior de Investigaciones Científicas, Madrid, 2003, Textos Universitarios, n. 6.

[9] J. Kunkel, Ars vitraria experimentalis, Leipzig (1689).

[10] Norma Española. Vidrio. Nomenclatura y Terminología. Cristal. Vidrio sonoro. UNE 43-603-79.

[11] Norma Española. Ensayos de vidrio. Determinación dilatométrica de la temperatura de transformación. UNE-43-703-78.

[12] W. Vogel, A. Rehfeld, H. Ritschel, Über die Verteilung farbloser und farbigen Zusatzkomponenten in einfachen Gläsern sowie ihr Einfluss auf Struktur und Kristallisation, Silic. Industr. 3 (5) (1967) 161-171.

[13] J.W. Cahn, J.E. Hilliard, Free energy of a nonuniform system I. Interfacial energy, J. Chem. Phys. 28 (1958) 258-267.

[14] A.J. Andrews, G.L. Clark, H.W. Alexander, The determination by X-ray-methods of crystalline compounds causing opacity in enamels, J. Amer. Ceram. Soc. 16 (1933) 385-392.

[15] H. Schönborn, Aufbau und Eigenschaften der Phosphat-Trübgläser, Silikattechn. 10 (8) (1959) 390-400.

[16] W.A. Weyl, Phosphates in ceramic ware I. In opal glasses, J. Amer. Ceram. Soc. 24 (7) (1941) 221-225. 